\title{
A REVISTA REALIDADE: TEXTOS E CONTEXTOS
}




\section{A REVISTA REALIDAdE: TEXtos e CONTEXTOS}

Resumo:

A partir dos Estudos Culturais, este trabalho faz uma leitura do texto e contexto histórico da publicação da revista REALIDADE n 10 e sua reedição em 2010. A edição fez um panorama da mulher brasileira em 1967, porém foi confiscada judicialmente por apresentar conteúdo obsceno. A reedição apresenta na íntegra o exemplar proibido. Os resultados mostram uma realidade ditatorial de controle social, um contexto de desigualdade nas relações de gênero e preconceituoso com as mulheres.

Palavras chave: Revista Realidade; Contexto; Estudos Culturais

\section{REALITY MAGAZINE: TEXTS AND CONTEXTS}

Abstract:

From the Culture Studies, this paper makes a reading of the text and context historic of the publication of magazine REALIDADE $\mathrm{n}^{\circ} 10$ and your reissue in 2010. The edition made a panorama of the Brazilian woman in 1967, but it was confiscated in court because it displays obscene content. The reissue presents the full copy prohibited. The results show a dictatorial reality of social control, a context of inequality in gender relations and prejudicial to women.

Keywords: Realidade Magazine; Context; Cultural Studies

\section{LA REVISTA REALIDADE: TEXTOS Y CONTEXTOS}

Resumen:

A partir de los estudios culturales, este trabajo hace una lectura del texto y contexto histórico de la publicación de la revista Realidad n 10 y su reedición en 2010. La edición hizo un panorama de la mujer brasileña en 1967, sin embargo fue confiscada judicialmente por presentar contenido obsceno. La reedición presenta en la integra el ejemplar prohibido. Los resultados muestran una realidad dictatorial de control social, un contexto de desigualdad en las relaciones de genero y preconceptos con las mujeres.

Palabras Clave: Revista Realidad; contexto; Estudios culturales 


\section{OS ESTUDOS DE CULTURA}

Para este texto, leva-se em consideração os Estudos Culturais de origem britânica, cuja organização se deu através do Centre for Contemporary Cultural Studies (CCCS), fundado em 1964 por Richard Hoggart. As idéias que foram desenvolvidas focavam as relações entre a cultura e a sociedade: "As relações entre a cultura contemporânea e a sociedade, isto é, suas formas culturais, instituições e práticas culturais, assim como suas relações com a sociedade e as mudanças sociais, vão compor o eixo principal de observação do CCCS." (ESCOSTEGUY, 2001).

Não existe um consenso universal sobre a origem deste campo de estudos, a versão dominante cita três autores como precursores, pois apresentavam preocupações com os temas cultura e sociedade: Richard Hoggart, com a obra Os usos da literatura (1957); Raymond Williams com Cultura e Sociedade (1958); e E.P. Thompson, The Making of the English Working-class (1963). Além desses, Stuart Hall também teve papel importante nos estudos sobre cultura do CCCS. O projeto dos Estudos Culturais não é um modelo de comunicação, seus questionamentos extrapolam o campo da comunicação (ESCOSTEGUY, 2001).

O conceito de cultura, tratando-se de forma geral, foi usado ao longo da história de várias formas. Fala-se da cultura agrícola ou de animais para fazer referêcia a um determinado tipo de plantio (a cultura do trigo, por exemplo). No lluminismo, cultura era sinônimo de civilização e progresso. Já no Romantismo era o modo específico de viver de um povo (o nacionalismo, por exemplo), era também sinônimo de cultura erudita, de artes, ciências, etc. Há também a diferenciação entre alta cultura e cultura de massa, como um eixo cultural, talvez. Muitos pensadores, como os da Escola de Frankfourt, por exemplo, não consideram a existência da cultura de massa. Para os Estudos Culturais é diferente, a cultura dos operários do pós-guerra teve grande influência. Os estudiosos promoveram um conceito diferente de cultura: o de modo de vida. Resumindo, todos têm cultura, não existe mais ou menos cultura, existem culturas diferentes. A cultura envolve poder, porém não é um campo autônomo nem só externamente determinado. Ou seja, tem especificidades, forma o ser humano, depende da economia, da política, das ideologias.

A "novidade" dos Estudos Culturais é que não mais se considera somente a lógica da sociedade, mas sim a influência que o sujeito tem no seu próprio ser social, a ponto, talvez, de grandes movimentos sociais serem mais fortes que a própria sociedade, podendo modificá-las. Por exemplo, o movimento feminista, que ao longo da história ajudou a promover mudanças em uma sociedade rígida, patriarcal, machista, masculina. Com relação a isso, de maneira geral, a sociedade é mais livre e igualitária nas suas relações de gênero, atualmente. 


\section{CIRCUITO DA CULTURA}

Para este trabalho utilizam-se algumas noções básicas de contexto cultural e análise textual inseridas no circuito da cultural proposto por Johnson (2006). Os estágios deste circuito cultural (produção - texto - leituras - culturas vividas) são apresentados como momentos diferentes, porém estão sempre interligados entre si, sendo dependentes e indispensáveis uns dos outros. Este entendimento é de suma importância na análise de produtos midiáticos sob o viés dos Estudos Culturais (ESCOSTEGUY, 2007).

Para Johnson (2006) o "texto" não é estudado por ele próprio, mas pelas formas subjetivas ou culturais que ele efetiva e torna disponível. O "texto" é apenas um meio no Estudo Cultural. A análise do texto exige cuidado, já que as leituras de um analista podem diferir da leitura real (do público) do produto. Johnson (2006) esclarece:

O isolamento de um texto com vista a uma análise acadêmica,é uma forma muito específica de leitura. De forma mais cotidiana, os textos são promiscuamente encontrados; eles caem sobre nós de todas as direções, através de meios diversificados e coexistentes e em fluxos que têm diferentes ritmos. Na vida cotidiana, os materiais textuais são completos, múltiplos, sobrepostos, coexistentes, justapostos; em uma palavra, "intertextuais" (JOHNSON, 2006 p. 88). Isso leva ao objetivo deste trabalho, a centralidade do contexto. Johnson(2006) afirma que o contexto determina o significado, as transformações, na medida que inclui tanto elementos culturais, sociais, políticos, como também situações imediatas e específicas, como o contexto particular de leitura (o ambiente doméstico, por exemplo). O contexto é crucial na produção social de significado.

\section{A REVISTA REALIDADE E O CONTEXTO SÓCIO-POLÍTICO DO BRASIL EM 1967}

Tomando a questão contextual como ponto de partida, a seguir o corpus será analisado e contextualizado. A escolha do objeto é motivada pela curiosa reedição da revista REALIDADE sobre a mulher brasileira, censurada há 44 anos.

Em janeiro de 1967, em pleno regime militar, com governo de Castello Branco (de 1964 a 1967), uma nova Constituição foi imposta, institucionalizando o governo militar e suas formas de atuação. Durante o governo Castello Branco os partidos políticos foram dissolvidos e a eleição indireta para presidente foi estabelecida, o que levaria ao poder, no mesmo ano, o general Arthur da Costa e Silva. No mês da imposição da Constituição Federal é que a revista REALIDADE $n^{\circ} 10$ foi lançada (e confiscada). Segundo Roberto Civita ${ }^{1}$ pelo

1Roberto Civita foi diretor de redação da REALIDADE, hoje é editor da VEJA e presidente do Conselho de Administração do Grupo Abril. As informações apresentadas neste trabalho foram retiradas do depoimento dele publicado no suplemento que acompanha a reedição da- 
menos 231 mil exemplares foram apreendidos diretamente na gráfica e outros quase 40 mil exemplares, que já estavam à venda nas bancas do Rio de Janeiro, foram apreendidos na rua. Assim mesmo, cerca de 200 mil exemplares foram salvos pelos jornaleiros e vendidos clandestinamente nos meses seguintes.

Vinte e um meses depois, em outubro de 1968, às vésperas do Ato Institucional $n^{\circ} 5^{2}$, em uma decisão do Supremo Tribunal Federal, a revista foi liberada, porém os exemplares apreendidos já haviam sido completamente triturados. Duas semanas antes da decisão do Supremo, a Editora Abril lançou a revista VEJA, em circulação até os dias atuais.

\section{POR QUE A REALIDADE ERA DIFERENTE?}

A revista REALIDADE foi lançada em 1966 e desde a primeira edição propunha uma revista diferente, ousada, criativa e profunda. A principal diferença para as publicações da época era a base jornalística. Segundo Carlos Marão, ex -editor da revista, a dedicação para a investigação era feita o tempo que fosse preciso. Além disso, trazia recursos inéditos de execução, textos longos e completos, e um fotojornalismo peculiar. A revista virou um fenômeno editorial, alcançando no primeiro semestre de publicação a marca histórica de um milhão e meio de leitores. Entre 1966 e 1973 recebeu 9 Prêmios Esso ${ }^{3}$. Cada edição era temática (Juventude, Amazônia, Nordeste...) e primava pela qualidade das informações e pela quebra de tabus, o que incomodava a alguns e agradava a muitos. Chegou a ter a colaboração de grandes artistas, como Carlos Drummond de Andrade, Plínio Marcos e Adoniran Barbosa. A revista não resistiu à pressão do governo militar6 e publicou o último exemplar em março de 1976.

\section{A EDIÇÃO CONFISCADA E A VEJA MULHER}

Em janeiro de 1967, a décima edição da revista REALIDADE (Tema: A muIher brasileira, hoje) foi tirada de circulação por ordem judicial, os motivos: imoralidade e obscenidade. Conta-se que a edição demorou meses para ficar pron$\mathrm{ta}^{4}$. Para se ter uma ideia da importância daquela edição, chegou-se a defini-la

quela REALIDADE, em junho de 2010.

$2 \mathrm{O}$ Al 5 foi o instrumento que deu ao regime poderes absolutos e cuja primeira conseqüência foi o fechamento do Congresso Nacional por quase um ano. Dezenas de jornais, revistas, rádios e emissoras de TV foram ocupadas por censores. A partir daí muitos jornalistas foram presos.

3Importante prêmio conferido a profissionais de imprensa no Brasil desde 1955.

4Em 1967 os militares promulgaram a Lei de Imprensa, que garantia ao governo censurar as publicações e punir quem escrevesse reportagens que ofendessem a moral ou colocasse em risco a segurança nacional. Paralelo a isso, o Serviço de Censura e Diversões Públicas (SCDP) proibiu até os anos 70 cerca de 500 filmes, 450 peças teatrais, 200 livros e 200 letras de música. 
como o mais profundo e amplo retrato jamais feito da mulher brasileira5

Em junho de 2010 a Editora Abril lançou simultaneamente uma Edição da revista VEJA Mulher (16 anos depois da última edição especial deste tipo) e a reedição da revista REALIDADE, proibida 44 anos antes, que foi acompanhada por um suplemento comentando os bastidores da apreensão da "edição proibida" durante o Brasil da ditadura militar.

O corpus deste trabalho é composto pelas três publicações: a Edição VEJA Mulher, por contextualizar na atualidade o acontecimento histórico de censura; a REALIDADE (reedição de 1967) e o suplemento já citado. Embora vendidas separadamente, é possível fazer uma leitura conjunta dos materiais. Por mais que este seja um estudo qualitativo, não se pretende aqui fazer uma leitura conclusiva ou com objetivo de esgotamento, pelo contrário, este é apenas uma exercício de leitura.

Começo pela VEJA Mulher pelo único e simples fato de tê-la comprado primeiro, e porque esta leitura motivou a busca e a curiosidade pela reedição da "Proibida" (que vem acompanhada do suplemento). A capa da VEJA Mulher é apresentada em tons de cor azul (assim como a REALIDADE $n^{\circ} 10$ ), com a imagem de pernas femininas cruzadas e um efeito de espelho. As manchetes são chamativas, anunciando uma revolução (vivida pelas mulheres) e alguns temas que visivelmente remetem ao passado, ao histórico de comportamento e conquistas femininas. No canto inferior direito a capa ainda mostra a imagem de uma lupa sobre uma figura de outra capa de revista (supostamente). O efeito de lente de aumento da lupa coloca em destaque uma figura feminina e algumas frases que parecem fora de época, como confissões de uma moça livre. Digo fora de época porque não me parece atual falar em "moça livre", afinal diz-se, as mulheres são livres, atualmente. A imagem é justamente da capa da revista REALIDADE, a proibida. Quem não sabe do fato histórico que envolve esta edição precisa abrir a VEJA Mulher para entender do que se trata (no momento da minha primeira leitura, foi o caso).

No interior da revista, logo na Carta ao Leitor, espaço primeiro de apresentação da edição aos leitores, quem lê precisa fazer uma escolha: Ou fecha a revista e vai à banca comprar outra; ou segue lendo e deixa-se motivar pela curiosidade, mas vai à banca depois. Me explico: esta apresentação conta a história da Edição 10 da REALIDADE, admite que a VEJA Mulher buscou inspiração nela e ainda propõem um diálogo entre as publicações, anunciando que a Editora Abril lançou aquela reedição. Escolha difícil e custosa para o bolso (ou rentável para a Editora, depende do ponto de vista). Escolho a primeira opção por hora, porque, afinal, quase todo o resto do conteúdo da VEJA Mulher remete à REALIDADE, então vamos direto à fonte.

5"Tudo nesta edição trata de mulher. Trabalhando, amando, rezando, pensando, falando... sendo. Sabemos que o panorama traçado é apenas parcial, mas esperamos que sirva para mostrar o muito que elas já fizeram e o mais que ainda irão fazer." (CIVITA, Roberto. In: REALIDADE, Janeiro 1967. Reedição Junho 2010). Grifos do autor. 
Primeiramente alguns dados curiosos. Em 1967 a REALIDADE realizou uma pesquisa ${ }^{6} \mathrm{com} 1200$ mulheres sobre diversos temas, como casamento, sociedade e eleições. Em 1994, em outra Edição da revista VEJA Mulher repetiu-se a pesquisa e em $2010^{7}$ novamente as mesmas perguntas foram feitas para 1000 mulheres. Estas pesquisas interessam de maneira especial nossa visão desde os estudos sobre cultura e sociedade, porque a comparação dos três momentos ajuda a entender os avanços da posição da mulher na sociedade brasileira. As mulheres hoje são maioria em população, estudam mais e representam números maiores nas universidades. Por outro lado ainda ingressam menos no mercado de trabalho (mais que nos anos 60), e ganham menos que os homens. Elas têm menos filhos, casam mais tarde e sempre admitiram o aborto em casos extremos. As mulheres têm a mesma necessidade de sexo que os homens, mas não acham que isso seja o mais importante na relação e jamais a infidelidade se justifica, isso não mudou ao longo do tempo.

O direito feminino ao emprego (e ao sucesso profissional), nas mesmas condições masculinas, é uma das conquistas definitivas do nosso tempo. As mulheres hoje dizem sim ao trabalho feminino, diferente de 1967, que a grande maioria (68\%) dizia que não era preciso as mulheres trabalharem se não fosse preciso. Ao longo do tempo elas passaram a acreditar que ambos os sexos poderiam obter êxito no trabalho. Os papéis sociais atribuídos às mulheres, como serem esposas, mães e donas de casa, já é coisa do passado. Enquanto antes $81 \%$ delas se realizavam cumprindo esses papéis, hoje a mesma percentagem não acha que isso é suficiente para a realização da mulher. Além disso cerca de $30 \%$ das mulheres se arrependeu de ter casado.

A comparação entre as pesquisas pode mostrar que a primeira, juntamente com a publicação da REALIDADE sobre a mulher brasileira, já previa uma série de mudanças no papel da mulher na sociedade. É neste sentido que o contexto é determinante neste texto, não apenas referente ao contexto sócio-político, como já foi abordado, mas também por todo um processo internacional de luta feminista, por direitos e desejos das mulheres que refletiu na sociedade brasileira.

A intenção aqui é entender o contexto da publicação daquela REALIDA$\mathrm{DE}$, a ditadura, a sociedade patriarcal machista e desigual nas relações de gênero. Vale lembrar que em 1967 as mulheres brasileiras já podiam cursar o ensino superior, já podiam votar ${ }^{8}$ e a pílula anticoncepcional já existia. Inclusive na pesquisa mostrou-se que $19 \%$ das mulheres tomavam pílula.

6Na apresentação da REALIDADE n 10, Roberto Civita define esta pesquisa como “o maior estudo de gênero jamais realizado no Brasil". Foram feitas 110 perguntas para cada uma das 1200 mulheres.

7Em 2010 a pesquisa foi realizada pelo Ibope. Ao longo da apresentação das pesquisas pela revista VEJA Mulher são utilizados também dados do IBGE 2008, da Fundação Carlos Chagas/ IBGE-Pnad e Fundação Carlos Chagas/MEC Inep-Seec/Censos de Ensino Superior, TSE e Pnad. 80 voto feminino foi regulamentado no Brasil em 1934. 
Entretanto é preciso ir ao texto para entender, afinal, o que a REALIDADE trazia de tão revolucionário, indecente e imoral para a época. Além da pesquisa já apresentada aqui, pelo menos sete reportagens apresentam casos, exemplos de vida, deram a palavra às mulheres: como uma entrevista com a atriz Ingrid Thulin, que já se considerava "livre" e não tinha medo de falar sobre sexo; e uma grande reportagem intitulada "Dona Berta, o diretor", que contou a história de uma empresária de sucesso. Nestes dois casos podemos notar que a história de vida e a postura de Igrid e Berta são apresentadas como exemplos de vida, de coragem feminina, de uma ideal de conquista, talvez, para as mulheres.

Os nomes femininos são preservados, em alguns casos, para preservar as mulheres da exposição pública, já que alguns assuntos não atendiam à moral e aos bons costumes da época, como é o caso de depoimentos de mulheres desquitadas, que sofriam proconceito na sociedade e da mãe solteira, que corajosamente se orgulhava da condição. Já estes exemplos são revolucionários no sentido de mostrarem a outras mulheres que é possível ser feliz sem os homens. Isso era realmente chocante para a época porque o desquite era uma vergonha, uma desonra para as mulheres, principalmente. O divórcio só foi criado no Brasil por lei em 1977. Ser mãe solteira hoje continua em pauta, continua sendo um problema, mesmo com as famílias mais modernas, mas no século passado não era apenas um problema, era motivo de condenação social, porque afinal ainda esperava-se delas que se casassem virgens.

A reportagem que supostamente 9 foi o principal motivo da proibição da REALIDADE, leva o título de "Nasceu!", contando a história da parteira Odila e mostrando em detalhes um parto normal, do início ao fim. Uma leitura hoje mostra uma reportagem bonita, com um texto bem escrito, detalhista e interessante, já que as parteiras viraram raridade, obviamente por uma questão de desenvolvimento, criação de hospitais, etc. Porém, em 1967, foi considerada uma afronta, indecente e imoral por mostrar fotos da criança nua e da mãe com as pernas abertas, no momento em que o bebê nascia. Pode ser que tenha gerado impacto, mas jamais alguma revista tinha mostrado imagens e conteúdos tão realistas, e por si só já foi diferente.

\section{CONSIDERAÇÕES}

Buscou-se neste trabalho uma contextualização da publicação da revista REALIDADE $n^{\circ} 10$, tirada de circulação em 1967. Quiseram apagar um material ousado, mas censura nenhuma foi capaz de apagar ou modificar a revolução sofrida (desejada e reivindicada) pelas mulheres brasileiras ao longo desse quase meio século. Ter a oportunidade de ler esta publicação hoje, 44 anos depois é essencial para valorizarmos o quanto é importante e significativo ser mulher,

9Nos relatos sobre o processo, apresentados no suplemento junto com a reedição, não fica claro qual foi o real motivo da censura, porém sujere que tenha sido esta matéria. 
principalmente porque milhares, antes da nossa geração, sofreram preconceito, indiferença, violência moral pelo fato de serem mulheres. Entender o ser mulher em diferentes épocas significa, de certa forma, entender como a cultura e a sociedade funcionam, e entender também as formas subjetivas pelas quais vivemos, por isso este trabalho vai ao encontro dos Estudos Culturais.

A leitura do texto nos permite voltar no tempo e sentir uma certa coragem por aquelas mulheres que falavam sem medo, que lutavam com força, que desejavam um mundo diferente para elas, mas que refletiu em conquistas para todas as mulheres que vieram depois. Os textos podem ser lidos como formas de representação:

[...] desde que se compreenda que estamos sempre analisando a representação de uma representação. O primeiro objeto, aquele que é representado no não, não é um evento ou um fato objetivo: ele vem com significados que lhe foram atribuídos a partir de alguma outra prática social (JOHNSON, 2006 p.107-108).

Se os textos são sistemas de representações, podemos entender através dele o que as mulheres do século passado viveram, como viveram e o que queriam viver. Talvez hoje a REALIDADE esteja sendo reeditada para que se torne pública a sua história, porém considerando o contexto brasileiro, no final dos anos 60 do século XX, ela pode ser considerada uma relíquia.

Este é apenas um exercício de leitura, que certamente motivará trabaIhos futuros, principalmente com relação a um desenvolvimento teórico que possibilite uma análise mais completa de textos e contextos culturais e sociais.

\section{REFERÊNCIAS}

ESCOSTEGUY, Ana C. Os estudos culturais. In: HOHLFELDT, Antônio; MARTINO, Luiz; FRANÇA, Vera Veiga (orgs). Teorias da comunicação: conceitos, escolas e tendências. Petrópolis, RJ: Vozes, 2001.

. Cartografias dos estudos culturais: uma versão latino-americana. Belo Horizonte:

Autêntica, 2004. . Circuitos de cultura/circuitos de comunicação: um protocolo analítico de integração de produção e recepção. In: Comunicação, Mídia e Consumo. ESPM. V.4, n.11, p. 115-135. São Paulo: ESPM, 2007.

JOHNSON, Richard. O que é, afinal, Estudos Culturais? In: SILVA, Tomaz Tadeu da (org.). 0 que é, afinal, Estudos Culturais? Belo Horizonte, Autêntica, 2006.

REVISTA VEJA MULHER, junho de 2010.

REVISTA REALIDADE, 1967, reedição em junho de 2010. 


\section{Janaina Cruz de Oliveira}

Formada em jornalismo. Mestranda pelo Programa de Pós-Graduação em Comunicação Social da PUCRS. É integrante do GEISC, Grupo de Pesquisa de Comunicação, Imaginário, Sociedade e Cultura. 